\title{
Root architecture might account for contrasting establishment success of Pseudotsuga menziesii var. menziesii and Pinus sylvestris in Central Europe under dry conditions
}

\author{
${\text { Barbara } \text { Moser }^{1} \text { - Christoph Bachofen }}^{1,2}$ • Jonathan D. Müller ${ }^{1,3} \cdot$ Marek Metslaid $^{4}$ • \\ Thomas Wohlgemuth ${ }^{1}$
}

Received: 6 October 2015 / Accepted: 15 July 2016 /Published online: 5 September 2016

(C) INRA and Springer-Verlag France 2016

\begin{abstract}
- Key message Pinus sylvestris seedlings quickly expand their roots to deeper soil layers while Pseudotsuga menziesii concentrates its root system in the topsoil, thereby running the risk of desiccation during long dry spells, as indicated by lower survival after simulated summer drought.

- Context Pseudotsuga menziesii (Douglas-fir) is regarded as a promising species to maintain the productivity of Central European lowland forests given the projected increase of long dry spells.
\end{abstract}

Handling Editor: Andreas Bolte

Contribution of the coauthors T. Wohlgemuth, B. Moser, C. Bachofen and M. Metslaid developed the idea and designed the experiment. The field work was carried out by C. Bachofen, M. Metslaid and J. Müller, supported by T. Wohlgemuth and B. Moser. C. Bachofen and J. Müller analysed the data; B. Moser, J. Müller and T. Wohlgemuth wrote the manuscript with editorial advice by the coauthors.

Electronic supplementary material The online version of this article (doi:10.1007/s13595-016-0574-1) contains supplementary material, which is available to authorized users.

Barbara Moser

barbara.moser@wsl.ch

Christoph Bachofen

christoph.bachofen@wsl.ch

Jonathan D. Müller

jonathan.muller@weizmann.ac.il

Marek Metslaid

marek.metslaid@emu.ee

Thomas Wohlgemuth

thomas.wohlgemuth@wsl.ch
- Aims Will the species be able to regenerate from seed and spread outside plantations in a drier temperate Europe?

- Methods We measured the relative growth rate, biomass allocation, root architecture, and phenotypic plasticity of Pseudotsuga menziesii seedlings sown in a common garden and grown under current precipitation and prolonged drought, respectively. The species' competitive ability with respect to Pinus sylvestris L., the most drought-tolerant native conifer in Central Europe, was assessed during three growing seasons.

- Results Pinus sylvestris seedlings had higher relative growth rates than did Pseudotsuga menziesii seedlings, first in terms of aboveground biomass and later in terms of shoot height. This resulted in heavier and taller seedlings after three growing seasons under both moist and dry conditions. Shorter vertical roots corresponded with lower survival of Pseudotsuga menziesii seedlings under dry conditions.

- Conclusion Fast root proliferation allows Pinus sylvestris seedlings to reach deeper water pools that are less rapidly depleted during transient drought. By contrast, the shallow root system might put Pseudotsuga menziesii seedlings at the risk of desiccation during prolonged dry spells.

1 Forest Dynamics, Swiss Federal Institute for Forest, Snow and Landscape Research WSL, Zürcherstrasse 111, 8903 Birmensdorf, Switzerland

Department of Environmental Sciences, Swiss Federal Institute of Technology, Universitätsstrasse 16, 8092 Zürich, Switzerland

3 Weizmann Institute of Science, 234 Herzl St, 7610001 Rehovot, Israel

Institute of Forestry and Rural Engineering, Estonian University of Life Sciences, Kreutzwaldi 5, 51014 Tartu, Estonia 
Keywords Drought tolerance - Phenotypic plasticity . Seedling mortality; · Douglas-fir $\cdot$ Scots pine

\section{Introduction}

Projections of climatic change have amplified the debate on whether tree species composition in European forests has to be actively managed in order to guarantee forest continuation, protection against natural hazards and economically important timber production in the coming century (Bussotti et al. 2015; Lindner et al. 2014; Wohlgemuth 2015). Foresters have long been studying non-native tree species that could enhance wood production under current climatic conditions. As such, Pseudotsuga menziesii (Mirb.) Franco (Douglas-fir) was first introduced to increase wood production (González-García et al. 2013). Today, about $2 \%$ of the German and $3 \%$ of the French forest area, respectively, are stocked with Pseudotsuga menziesii, and the species is expected to become the third most important conifer in Europe after Picea abies (L.) H. Karst. (Norway spruce) and Pinus sylvestris L. (Scots pine; Schmid et al. 2014). It is regarded as a promising alternative to Picea abies in commercial lowland forests under future climatic conditions (Brang et al. 2008; Fischer 2008). More recently, it has even been suggested that Pseudotsuga menziesii might be able to grow in regions as dry as the Central Alpine valleys (Chen et al. 2010; Eilmann and Rigling 2012), although such drought tolerance is still up for debate (Littell et al. 2008; Sergent et al. 2014). The expansion of Pseudotsuga menziesii in Central European forests is, however, increasingly criticised by nature conservationists, who fear negative effects of nonnative species on biodiversity and forest functioning (Schmid et al. 2014). Taking such concerns into account, the question of how well exotic tree species will be adapted to future climatic conditions and might be able to outcompete native species gains importance (Schüler et al. 2014).

The most drought-resistant native conifer in Central Europe is Pinus sylvestris (Braun-Blanquet 1961; Ozenda 1985). In particular, Central Alpine populations are known for their high phenotypic plasticity, which enables them to grow in changing environments (Richter et al. 2012). Nevertheless, Pinus sylvestris has suffered high mortality in dry Alpine valleys after the exceptional summer drought in 2003, for instance in the Valais, Switzerland (Bigler et al. 2006; Rigling et al. 2013) and the Aosta valley, Italy (Vacchiano et al. 2012). As a result, adequate management measures (Vacchiano and Motta 2015) and potential alternatives to Pinus sylvestris, such as Pseudotsuga menziesii, have been investigated (Eilmann and Rigling 2012). These studies have, however, focused on planted seedlings, which until now are common practice in Central Europe but are costly and may necessitate irrigation, especially in dry years. Planted Pseudotsuga menziesii seedlings are known to grow faster (Nabel et al. 2013) and have different root morphologies (Preisig et al. 1979) than seedlings grown from seed. Relying on natural regeneration or direct seeding might be more cost-efficient if the species should be managed at larger scales in the future. Assessing the ability of Pseudotsuga menziesii to establish from seed under future climatic conditions will further allow to evaluate its potential to spread outside managed forests and invade habitats where it is undesirable, as e.g. in nature reserves. This is important since Pseudotsuga menziesii has a high reproductive potential once it reaches maturity (Richardson and Rejmánek 2004). As in all plant species, the competitive ability of tree seedlings is determined by their ability to acquire resources such as light, water and nutrients (Rewald and Leuschner 2009; Schulte et al. 2013). Seedling establishment and successful regeneration are thus to a large extent driven by the soil exploitation strategy of a species and its belowground interaction with neighbouring species (Messier et al. 2009). High rates of root extension (Zhang et al. 2012) and the ability to quickly occupy a large soil volume seem to be major attributes of competitive species (Mommer et al. 2011; Rajaniemi 2007). The competitive hierarchy of coexisting species may change with resource availability, depending on the plasticity of a species' root system in response to stress (Fort et al. 2014; Zhang et al. 2012). Consequently, the morphology and plasticity of the root system are crucial parameters to assess a species' ability to successfully establish and compete under current and future climatic conditions. Like most pines species, Pinus sylvestris produces a taproot already during the earliest seedling stages (Wilcox 1968), reaching up to $40-\mathrm{cm}$ soil depth within 6 months after germination (Moser et al. 2015) and allowing it to acquire water from deeper soil layers that are less rapidly depleted during drought events (Ryel et al. 2008). By contrast, little is known about the root architecture of Pseudotsuga menziesii seedlings during early establishment (but see Preisig et al. 1979 for 5-8-year-old seedlings), while 10-80-year-old Pseudotsuga menziesii were shown to have a superficial root system (Mauer and Palatova 2012), which only slowly advances to deeper soil layers (Domec et al. 2004).

The aim of the present study was to assess the relative competitive abilities of Pseudotsuga menziesii and Pinus sylvestris seedlings in Central European lowland forests under current climatic conditions and aggravated, climate changetype drought. Both species were sown in a common garden in the presence of interspecific and intraspecific competition and grown for 3 years either under current summer precipitation or 4 months of summer drought during the second and third growing season. The competitive ability of the two species was assessed in terms of relative growth rate, and their establishment success was related to biomass allocation, root architecture and phenotypic plasticity. 


\section{Material and methods}

\subsection{Species and seed material}

Pseudotsuga menziesii (Mirb.) Franco is a widespread tree species in western North America ranging from Canada to Mexico (Little 1971). Two subspecies are distinguished, var. glauca and var. menziesii. The latter was introduced to Europe in 1827 and first cultivation trials took place in Central Europe by the end of the nineteenth century (Kowarik and Rabitsch 2010; Tschopp et al. 2015). Pseudotsuga menziesii var. glauca - the more drought-resistant inland variety native to the Rocky Mountains - occurs in a wide range of mesic to xeric sites (Ferrell and Woodard 1966). This variety has been shown to be very susceptible to Rhabdocline pseudotsugae, a fungal needle cast present in North America (Blada 1971; Hoff 1987), which has spread to Europe starting in 1914 causing a huge damage in Douglas-fir plantations (Bürgi and Diez 1986; Stimm and Dong 2001). Therefore, the coastal variety (var. menziesii) is now grown almost exclusively in European forests. In our experiment, we used seeds from commercial harvests of two Pseudotsuga menziesii var. menziesii populations, one from the west coast of the USA and one from a population introduced to Germany in the nineteenth century (Table 1). According to Eilmann et al. (2013), coastal populations of Pseudotsuga menziesii in the USA increase their productivity and, concomitantly, decrease their drought resistance along the latitudinal gradient from south to north. Consequently, the US population included in our experiment may be considered as both intermediately productive and intermediately drought tolerant. Unfortunately, we were not able to trace the origin of the German population, but we expect a potential adaptation to European environmental conditions since its introduction in the nineteenth century.

Pinus sylvestris $\mathrm{L}$. is the most drought-tolerant conifer in Central Europe ranging from the Mediterranean to Siberia (http://www.euforgen.org/distribution-maps/). In Central Alpine valleys, it forms stands between 500 and $1500 \mathrm{~m}$ a.s.
1. We collected seeds from a low elevation (Leuk) and a high elevation (Visperterminen) population in the Central Alpine Rhone valley (Table 1), the driest regions in Switzerland. In both populations, seeds were collected from five maternal lineages in winter 2011/2012.

\subsection{Experimental setup}

Pseudotsuga menziesii and Pinus sylvestris were grown in mesocosms $(200 \mathrm{~cm} \times 80 \mathrm{~cm} \times 50 \mathrm{~cm})$ in a common garden near Leuk (Valais, Switzerland; 46 $18^{\prime} 33^{\prime \prime}$ N, $07^{\circ} 41^{\prime} 10^{\prime \prime}$ E; $610 \mathrm{~m}$ a.s.1.). The mesocosms were filled with $30 \mathrm{~cm}$ of sand and gravel from the local Rhone riverbed (subsoil), covered by $15 \mathrm{~cm}$ of humus (Oekohum GmbH, Herrenhof, Switzerland; topsoil), similar to the two-layered forest soils of the Rhone valley with a parent material horizon and an organic surface horizon (Richter et al. 2012). All mesocosms were shaded with white knitted polypropylene shade cloth that blocked out $22 \%$ of the sunlight, generating light to medium shade conditions optimal for Pseudotsuga menziesii seedling establishment (Brodie and DeBell 2013; Mailly and Kimmins 1997). The mesocosms were arranged in a split-plot design with five blocks (whole plots), each containing two mesocosms (split plots) exposed to differing watering regimes (control and drought, respectively; Online Resource1a). Each mesocosm was divided into two half-mesocosms, which represents a second level of blocking to minimise the effect of unknown nuisance factors. Each half-mesocosm consisted of 70 squares of $10 \mathrm{~cm} \times 10 \mathrm{~cm}$, which were sown with 15 seeds of one of the 2 Pinus sylvestris populations (either Leuk or Visperterminen) or 20 seeds of one of the 2 Pseudotsuga menziesii populations (either Germany or USA) between March 20 and 23, 2012. Each population was sown in 5 squares per half-mesocosm, i.e. a total of 20 squares. The remaining 50 squares contained Mediterranean populations of Pinus sylvestris, Pinus nigra Arnold and Pinus halepensis Mill., which are not part of the present study (details in Online Resource 1b). We used a higher seed density in Pseudotsuga

Table 1 Origin of Pinus sylvestris and Pseudotsuga menziesii seeds sown in the common garden at Leuk (Switzerland) and climatic conditions at the seed origin (average annual temperature and annual precipitation sum; means 1950-2000)

\begin{tabular}{|c|c|c|c|c|}
\hline \multirow{2}{*}{$\begin{array}{l}\text { Species } \\
\text { Origin }\end{array}$} & \multicolumn{2}{|l|}{ Pinus sylvestris } & \multicolumn{2}{|c|}{ Pseudotsuga menziesii } \\
\hline & Leuk Switzerland & Visperterminen Switzerland & Snoqualmie USA & Tauberbischofsheim Germany \\
\hline Status & Autochthonous & Autochthonous & Autochthonous & Introduced \\
\hline Latitude & 46.29 & 46.27 & 47.53 & 49.63 \\
\hline Longitude & 46.29 & 46.27 & -121.82 & 9.65 \\
\hline Elevation (m a.s.l.) & 570 & 1360 & 500 & 370 \\
\hline Temperature $\left({ }^{\circ} \mathrm{C}\right)$ & 9 & 5.1 & 10.1 & 9.4 \\
\hline Precipitation (mm) & 812 & 1317 & 1608 & 674 \\
\hline
\end{tabular}

Climatic data provided by MeteoSwiss (Pinus sylvestris) and www.worldclim.org (Pseudotsuga menziesii; Hijmans et al. 2005) 
menziesii to balance its inferior seed quality (Online Resource 2). After sowing, all mesocosms were watered regularly until May 31, 2012, to maximise emergence. Starting from June 1, 2012, automatic transparent rain shelters were used to intercept natural rainfall during the growing season (June-September 2012, end of March-end of September 2013 and 2014). During these periods, the mesocosms were irrigated automatically in two consecutive nights per week (Richter et al. 2012). In the control treatment, $151 \%$ of the average April-September precipitation in the Rhone valley, i.e. $416 \mathrm{~mm}$ from the end of March to the end of September, was applied to individual mesocosms. This corresponds to the top decile of the longterm rainfall measured at the nearby MeteoSwiss station in Sion from 1864 to 2011. The drought treatment consisted of the same irrigation treatment as the controls in 2012 as well as from the end of March until the end of May 2013 and 2014, but it included a complete summer drought without irrigation from the beginning of June to the end of September 2013 and 2014 (Online Resource 3). This represents an increase in long dry spells as projected for Central Europe by the end of the century (Lindner et al. 2014). Mesocosms were subjected to natural rainfall from the end of September to the end of March. Volumetric soil water content was recorded in both treatments with EC-5 soil moisture sensors (Decagon, Pullman, USA) installed at 5- and 40-cm soil depths (Online Resource 3). Although the soil water content was considerably lower in the subsoil than in the topsoil, this does not correspond to plant available water because soil texture differed substantially between the two layers. The permanent wilting point of humus exceeds $20 \%$ (Zuber 2007) whereas that of a sandy/gravelly soil lies between 2 and $4 \%$ (Singer and Munns 2006). In the topsoil, the permanent wilting point was therefore reached approximately within 1 month after the onset of the drought (cf. Online Resource 3). By contrast, it is difficult to define when plant available water reached critical levels in the subsoil because the accuracy of EC-5 soil moisture sensors is about $1-2 \%$ even after soil-specific calibration.

\subsection{Seedling emergence and survival}

Emergence rate in the mesocosms exceeded $75 \%$ in Pseudotsuga menziesii from the USA and both Pinus sylvestris populations, which is slightly lower than the germination rate under lab conditions (Online Resource 2). The quality of Pseudotsuga menziesii seeds from Germany was poor: while $46 \%$ of the seeds were germinated under lab conditions, only $27 \%$ emerged in the mesocosms. In order to ensure similar levels of competition among seedlings, the number of seedlings per square was reduced to four in April 2013, to two in October 2013 and to one in May 2014 by randomly selecting seedlings to be harvested/removed. According to Poorter et al. (2012), plant growth in container or pot experiments is likely to be reduced when the total biomass exceeds $1 \mathrm{~g} \mathrm{~L}^{-1}$ soil volume. In our experiment, total plant biomass per mesocosm amounted to $0.4 \mathrm{~g} \mathrm{~L}^{-1}$ in September 2012, to 1.1 (control) and 0.7 (drought) $\mathrm{g} \mathrm{L}^{-1}$ in September 2013 and to 3.6 (control) and 1.6 (drought) $\mathrm{g} \mathrm{L}^{-1}$ in September 2014. This suggests that mesocosm size potentially limited the growth of control seedlings in 2014 but not in 2012 and 2013. Bigger mesocosms might have resulted in higher biomass of control seedlings and thus more pronounced treatment effects in 2014.

Due to the large number of replicates in the overall experiment $(5$ blocks $\times 2$ mesocosms $\times 2$ half-mesocosms $\times 70$ squares $=1400$ squares; cf. Online Resource 1), it was not feasible to regularly count the number of seedlings per square. The number of squares with living seedlings was recorded instead, although not for all the treatments and halfmesocosms at the same time (details in Online Resource 4). Direct calculations of seedling mortality are thus impossible and the proportion of squares with at least one living seedling was used as a surrogate of seedling survival. We are aware that this is a very rough estimate of survival, which underestimates mortality rates of individual seedlings. Nevertheless, we consider it crucial to have an approximate measure of survival in order to evaluate regeneration success.

\subsection{Biomass allocation, plant architecture and relative growth rate}

Plant architecture and biomass allocation were assessed in September 2013 and 2014 by excavating the seedlings of one randomly selected block. The following parameters were measured on one randomly selected seedling per square (two halfmesocosms per treatment $\times$ five squares per population $=$ ten replicates per treatment and population): the longest vertical root, the longest lateral root (Online Resource 5), shoot height (from the root collar to the insertion of the bud), shoot and root biomass (after drying to constant weight). In the non-excavated blocks, shoot biomass was measured at the end of each growing season, i.e. at the end of September 2012, 2013 and 2014, by randomly selecting five squares per mesocosm and population and harvesting one random seedling per square. Details on sample sizes are given in Online Resource 4. Relative growth rates $\left(V_{2013} / V_{2012}\right.$ and $\mathrm{V}_{2014} / \mathrm{V}_{2013}$ ) were calculated on an annual basis (September-September) for shoot and root biomass, shoot height and vertical and lateral root length.

\subsection{Data analyses}

Effects of the drought treatment, species and populations on shoot and root biomass, vertical and lateral root length and relative growth rates were tested with linear mixed effects models using the statistics program R (R Core Team 2015) and the lmer function of the lme4 package. Blocks were treated as a random effect and treatment, species and population as fixed effects with populations being nested in species. Since the lmer function does not provide $P$ values for the fixed effects, 
we calculated $P$ values using the lmerTest package. A simultaneous test for multiple comparisons of means using Holm adjustment was conducted with the glht function from the multcomp package (Hothorn et al. 2008). In 2013, only one seedling of the German Pseudotsuga menziesii population was present in the drought-stressed container of the block selected for the root harvest, thus statistical tests of root parameters neglect this population (cf. Figs. 1, 2 and 3).
2012
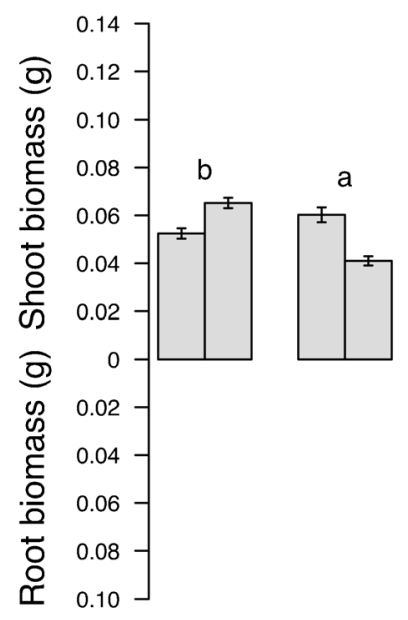

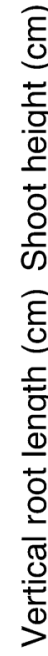
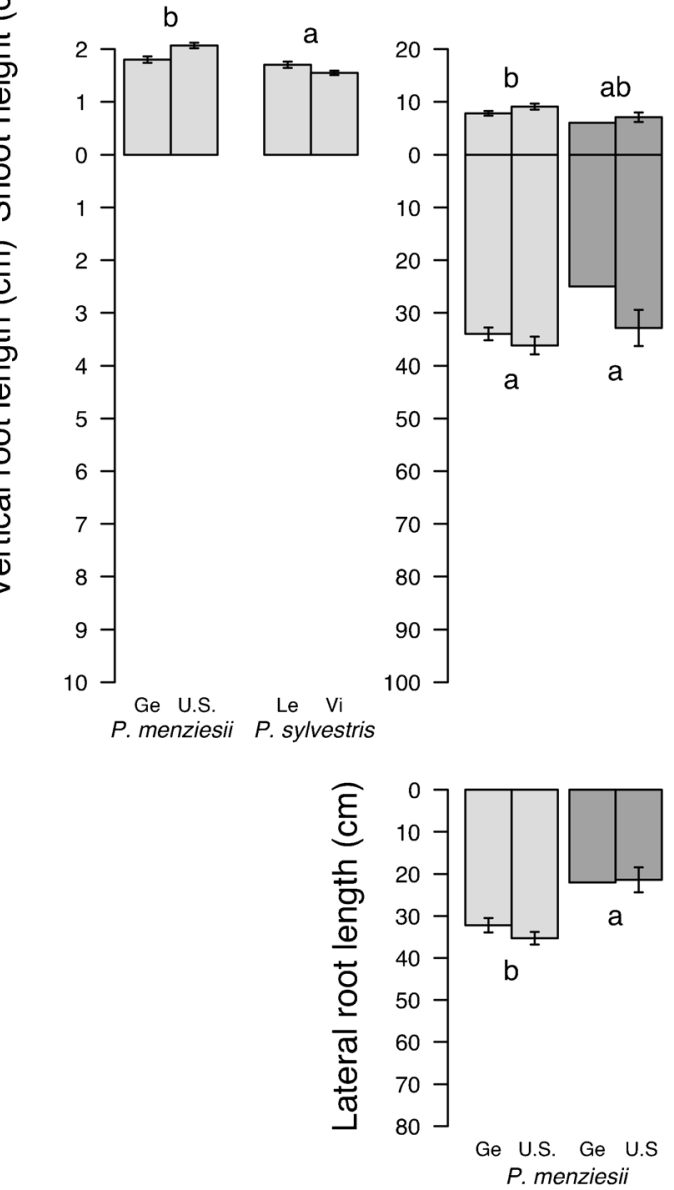

Fig. 1 Aboveground and belowground biomass, shoot height and vertical and lateral root length of 1- (2012), 2- (2013) and 3-year old (2014) Pseudotsuga menziesii and Pinus sylvestris seedlings growing under current precipitation (control) and recurrent, prolonged drought

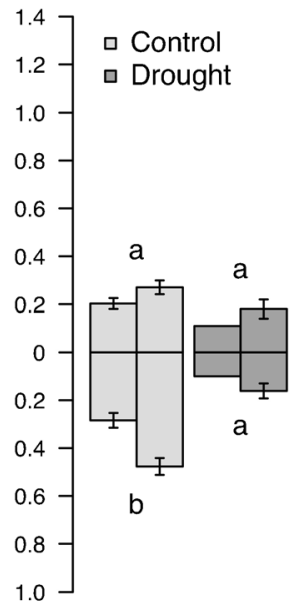

2013
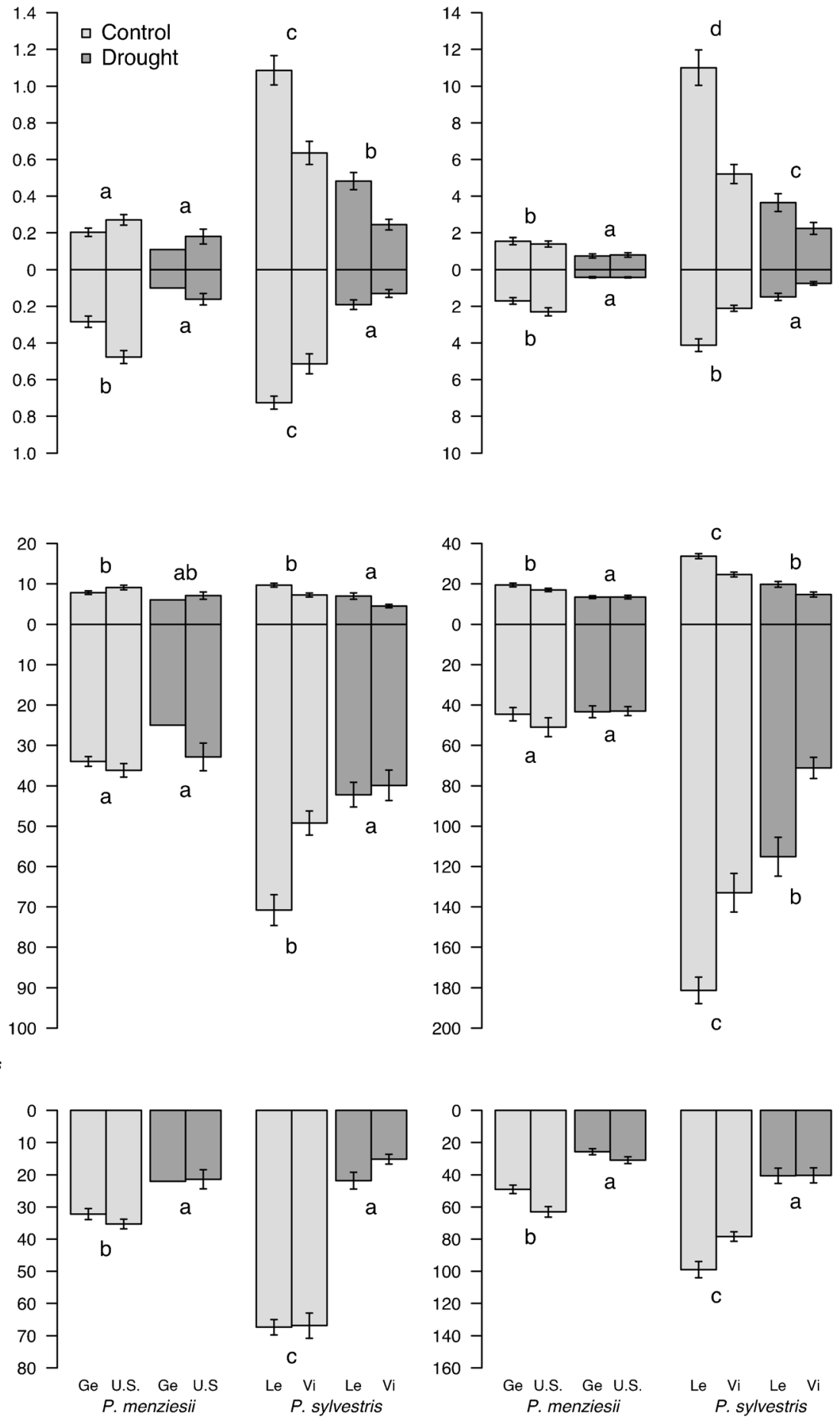

(2013 and 2014), respectively. Bars represent means \pm SE. Identical letters above/below two bars indicate no statistical differences between means in the same year. Note the different scales on the y-axis in different years 
Fig. 2 Relative growth rates of Pseudotsuga menziesii and Pinus sylvestris seedlings growing under current precipitation (control) and recurrent, prolonged drought (2013 and 2014), respectively: shoot biomass, shoot height, root biomass, vertical root length and lateral root length

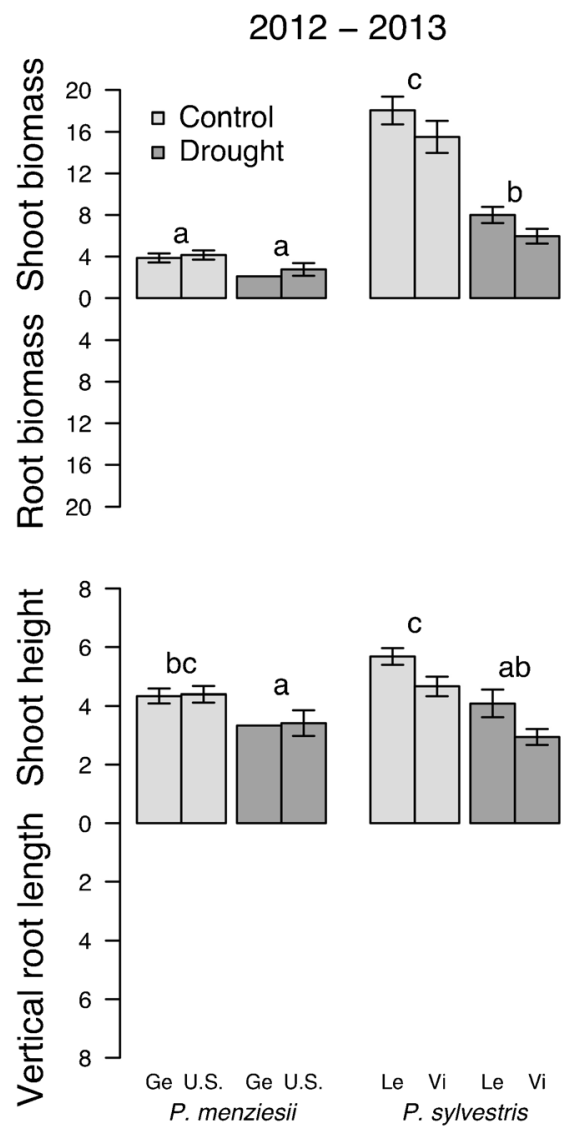

$2013-2014$
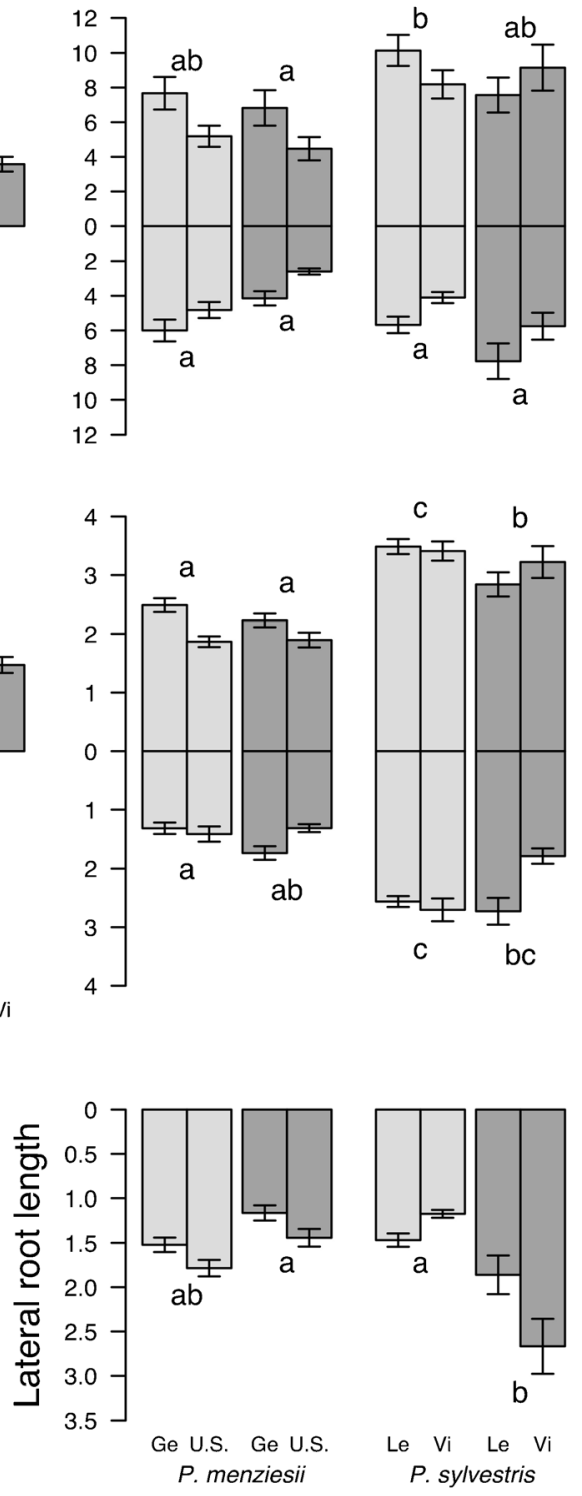

The phenotypic plasticity of individual species-population combinations was quantified using the relative distance plasticity index (RDPI) proposed by Valladares et al. (2006), which is based on phenotypic distances among individuals of a given speciespopulation combination exposed to different environments. In our study, RDPI was defined as the average of partial RDPIs for shoot biomass, root biomass, vertical root length and lateral root length.

\section{Results}

\subsection{Aboveground biomass and shoot height}

Pseudotsuga menziesii and Pinus sylvestris differed considerably in their temporal pattern of biomass allocation. While
Pseudotsuga menziesii seedlings had slightly more biomass and were slightly taller than Pinus sylvestris seedlings at the end of the first growing season (Fig. 1, Table 2), the growth rate of the aboveground biomass was considerably higher in Pinus sylvestris between 2012 and 2013 (Fig. 2, Table 3). Consequently, Pinus sylvestris seedlings were equally tall but heavier than the Pseudotsuga menziesii seedlings by the end of the second growing season (Fig. 1). Between 2013 and 2014 , both species grew at similar rates in terms of aboveground biomass, but Pinus sylvestris had a more pronounced shoot height growth than did Pseudotsuga menziesii (Fig. 2). The higher relative growth rates of Pinus sylvestris in terms of aboveground biomass 2012-2013 and in terms of shoot height 2013-2014 resulted in up to eight (control) and five (drought) times more aboveground biomass and two (control) and 1.5 
Fig. 3 Pseudotsuga menziesii (red) and Pinus sylvestris (black) seedlings grown under contrasting water conditions in a common garden in the Rhone valley, Switzerland. The seedlings were excavated from mesocosms $(200 \mathrm{~cm} \times 80 \mathrm{~cm} \times 50 \mathrm{~cm})$ at the end of the third growing season. Original photograph in Online Resource 5

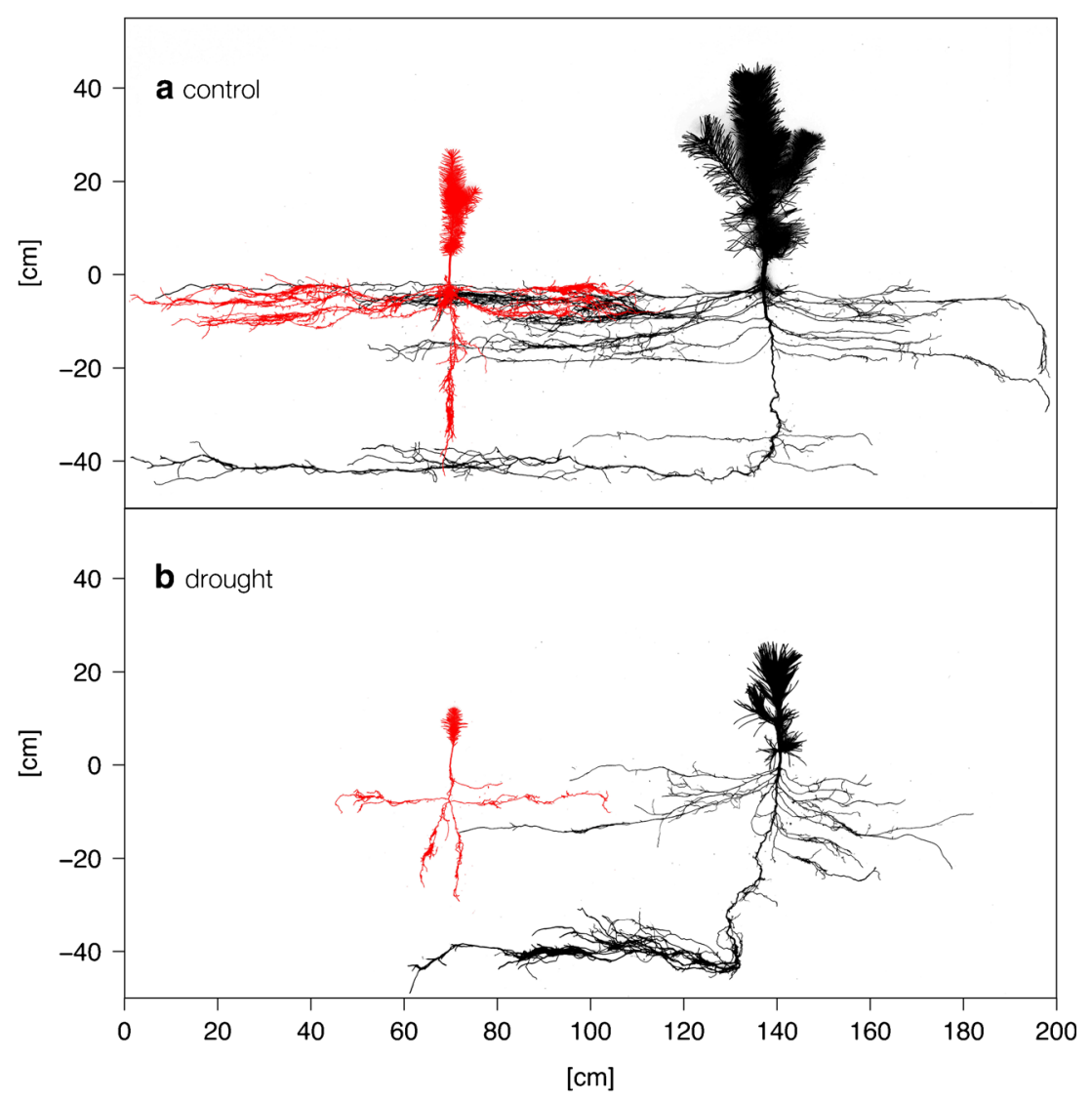

(drought) times taller seedlings by the end of the experiment (Fig. 1). Both species reduced shoot height growth in response to the drought between 2012 and 2013. Droughted Pinus sylvestris seedlings simultaneously diminished aboveground biomass growth and further reduced shoot height growth between 2013 and 2014 (Fig. 2, Table 3). As a result, droughted Pinus sylvestris seedlings reduced aboveground biomass to a larger extent than did
Pseudotsuga menziesii seedlings, but overall, they were still heavier and taller than Pseudotsuga menziesii after the third growing season (Fig. 1, Table 2). Populations differed in both species and all years with respect to both shoot biomass and shoot height. Population effects, however, were smaller than species (shoot biomass) or treatment (shoot height) effects, as indicated by the lower F-values (Table 2).

Table 2 Shoot and root biomass, shoot height and vertical and lateral root length of Pseudotsuga menziesii and Pinus sylvestris seedlings: ANOVA results for the effects of drought treatment (whole-plot factor), species (split-plot factor) and population (nested within species)

\begin{tabular}{|c|c|c|c|c|c|c|c|c|c|c|c|c|c|c|c|c|}
\hline \multirow[t]{2}{*}{ Year } & \multirow[t]{2}{*}{ Source of variation } & \multicolumn{3}{|c|}{ Shoot biomass } & \multicolumn{3}{|c|}{ Shoot height } & \multicolumn{3}{|c|}{ Root biomass } & \multicolumn{3}{|c|}{ Vertical root length } & \multicolumn{3}{|c|}{ Lateral root length } \\
\hline & & d.f. & $\mathrm{F}$ & $\mathrm{P}$ & d.f. & $\mathrm{F}$ & $\mathrm{P}$ & d.f. & $\mathrm{F}$ & $\mathrm{P}$ & d.f. & $\mathrm{F}$ & $\mathrm{P}$ & d.f. & $\mathrm{F}$ & $\mathrm{P}$ \\
\hline \multirow[t]{2}{*}{2012} & Species & 1,85 & 14.5 & $<0.001$ & 1,84 & 33.5 & $<0.001$ & & & & & & & & & \\
\hline & Population in species & 2,85 & 22.9 & $<0.001$ & 2,84 & 7.8 & $<0.001$ & & & & & & & & & \\
\hline \multirow[t]{4}{*}{2013} & Treatment & 1,47 & 29.9 & $<0.001$ & 1,100 & 20.4 & $<0.001$ & 1,62 & 71.5 & $<0.001$ & 1,52 & 15.8 & $<0.001$ & 1,61 & 111.5 & $<0.001$ \\
\hline & Species & 1,132 & 88.3 & $<0.001$ & 1,132 & 0.6 & 0.435 & 1,62 & 7.5 & 0.008 & 1,3 & 20.7 & 0.026 & 1,61 & 18.9 & $<0.001$ \\
\hline & Treatment $\mathrm{x}$ species & 1,131 & 1.9 & 0.171 & 1,132 & 0.5 & 0.469 & 1,62 & 0.8 & 0.376 & 1,52 & 5.7 & 0.020 & 1,61 & 27.1 & $<0.001$ \\
\hline & Population in species & 2,132 & 15.8 & $<0.001$ & 2,132 & 11.4 & $<0.001$ & 2,62 & 6.9 & $<0.001$ & & & & 2,61 & 1.2 & 0.316 \\
\hline \multirow[t]{4}{*}{2014} & Treatment & 1,178 & 80.5 & $<0.001$ & 1,178 & 105.4 & $<0.001$ & 1,60 & 99.1 & $<0.001$ & 1,60 & 18.4 & $<0.001$ & 1,59 & 88.7 & $<0.001$ \\
\hline & Species & 1,178 & 192.9 & $<0.001$ & 1,178 & 69.4 & $<0.001$ & 1,5 & 2.0 & 0.215 & 1,2 & 70.1 & 0.014 & 1,4 & 5.2 & 0.083 \\
\hline & Treatment $\mathrm{x}$ species & 1,178 & 7.0 & 0.009 & 1,178 & 14.2 & $<0.001$ & 1,60 & 0.4 & 0.515 & 1,60 & 13.6 & $<0.001$ & 1,59 & 3.5 & 0.067 \\
\hline & Population in species & 2,178 & 7.8 & $<0.001$ & 2,178 & 17.4 & $<0.001$ & 2,6 & 1.4 & 0.322 & & & & 2,4 & 0.6 & 0.574 \\
\hline
\end{tabular}

Bold font indicates $P$ values $<0.05$ 
Table 3 Relative growth rates of Pseudotsuga menziesii and Pinus sylvestris seedlings: ANOVA results for the effects of drought treatment (wholeplot factor), species (split-plot factor) and population (nested within species)

\begin{tabular}{|c|c|c|c|c|c|c|c|c|c|c|c|c|c|c|c|c|}
\hline \multirow[t]{2}{*}{ Period } & \multirow[t]{2}{*}{ Source of variation } & \multicolumn{3}{|c|}{ Shoot biomass } & \multicolumn{3}{|c|}{ Shoot height } & \multicolumn{3}{|c|}{ Root biomass } & \multicolumn{3}{|c|}{ Vertical root length } & \multicolumn{3}{|c|}{ Lateral root length } \\
\hline & & d.f. & $F$ & $P$ & d.f. & $F$ & $P$ & d.f. & $F$ & $P$ & d.f. & $F$ & $P$ & d.f. & $F$ & $P$ \\
\hline \multirow[t]{4}{*}{ 2012-2013 } & Treatment & 1,47 & 29.9 & $<0.001$ & 1,97 & 20.1 & $<0.001$ & & & & & & & & & \\
\hline & Species & 1,132 & 115.7 & $<0.001$ & 1,132 & 1.8 & 0.179 & & & & & & & & & \\
\hline & Treatment $\mathrm{x}$ species & 1,131 & 1.9 & 0.171 & 1,132 & 0.9 & 0.344 & & & & & & & & & \\
\hline & Population in species & 2,132 & 2.0 & 0.140 & 2,132 & 5.4 & 0.006 & & & & & & & & & \\
\hline \multirow[t]{4}{*}{ 2013-2014 } & Treatment & 1,178 & 4.7 & 0.032 & 1,178 & 6.2 & 0.013 & 1,60 & 0.5 & 0.465 & 1,67 & 0.0 & 0.957 & 1,60 & 1.7 & 0.193 \\
\hline & Species & 1,178 & 11.0 & 0.001 & 1,178 & 84.1 & $<0.001$ & 1,5 & 0.5 & 0.503 & 1,67 & 22.2 & $<0.001$ & 1,4 & 0.6 & 0.491 \\
\hline & Treatment $\mathrm{x}$ species & 1,178 & 0.7 & 0.420 & 1,178 & 2.1 & 0.148 & 1,60 & 6.3 & 0.015 & 1,67 & 3.3 & 0.075 & 1,60 & 14.3 & $<0.001$ \\
\hline & Population in species & 2,178 & 4.0 & 0.019 & 2,178 & 5.6 & 0.005 & 2,5 & 0.6 & 0.590 & 2,67 & 0.6 & 0.545 & 2,4 & 0.3 & 0.754 \\
\hline
\end{tabular}

Bold font indicates $P$ values $<0.05$

\subsection{Belowground biomass and root architecture}

The proportion of biomass allocated to roots was two to three times higher in Pseudotsuga menziesii than in Pinus sylvestris, irrespective of the treatment (2013 and 2014: $P<0.001$; Online Resource 6). In absolute terms, Pinus sylvestris seedlings had higher root biomass than did Pseudotsuga menziesii in the control treatment in 2013, but this difference disappeared in 2014 (Fig. 1, Table 2). Under dry conditions, both species drastically reduced root biomass and lateral root length, while vertical root length was only affected in Pinus sylvestris seedlings. Nevertheless, the vertical roots of Pinus sylvestris were distinctly longer than those of Pseudotsuga menziesii at the end of the third growing season, both under dry and control conditions. Relative growth rates of root biomass and vertical root length were unaffected by drought in both species, but Pinus sylvestris seedlings clearly expanded their lateral roots under dry conditions (Fig. 2, Table 3). Lateral root length of Pseudotsuga menziesii and Pinus sylvestris seedlings were similar under dry conditions (Fig. 1). In the controls, by contrast, Pinus sylvestris had longer lateral and vertical roots than did Pseudotsuga menziesii (Fig. 3).

\subsection{Phenotypic plasticity}

The contrasting responses of Pseudotsuga menziesii and Pinus sylvestris to the drought treatment with respect to shoot biomass and vertical root length are also reflected in the relative distance plasticity index (RDPI). While the Pinus sylvestris populations were moderately plastic in both years, the RDPI of the Pseudotsuga menziesii populations was considerably lower after the first summer drought (i.e. the second growing season; $P<0.001$, Fig. 4$)$. The plasticity of Pseudotsuga menziesii increased during the third growing season and reached similar levels as Pinus sylvestris in 2014 $(P=0.905)$.

\subsection{Seedling mortality}

We were not able to record the mortality of the individual trees, but the proportion of squares that contains living seedlings at a given point in time indicates that in the German Pseudotsuga menziesii population, mortality occurred already in April/May 2013, i.e. before the onset of the summer drought treatment (Fig. 5). Lower germination under lab conditions and lower emergence in the common garden compared to Pseudotsuga menziesii from USA (Online Resource 2) suggest that the seed quality of the German Pseudotsuga menziesii population was poor, which might be the cause of

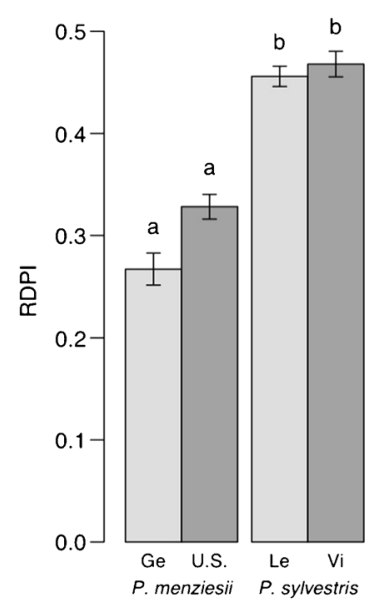

2013

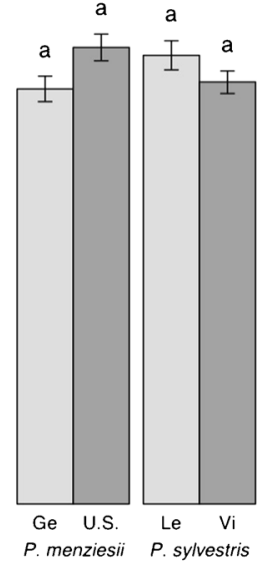

2014
Fig. 4 Phenotypic plasticity of Pseudotsuga menziesii and Pinus sylvestris populations in terms of the relative distance plasticity index (RDPI), which was calculated based on shoot biomass, root biomass, maximum vertical root length and maximum lateral root length. Identical letters above two bars indicate no statistical differences between means in the same year 


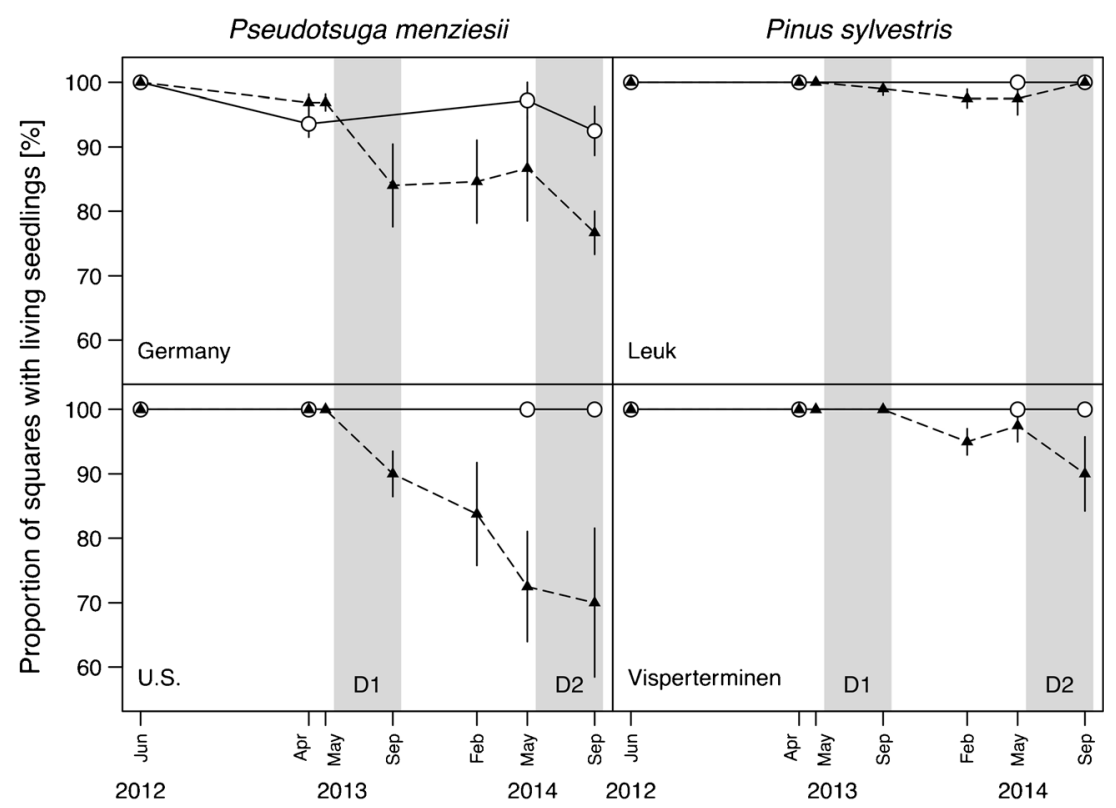

Fig. 5 Survival of Pseudotsuga menziesii and Pinus sylvestris seedlings of different origin in the course of the experiment measured in terms of the proportion of squares containing at least one living seedling. Black line and open circles denote the control treatment, dashed line and triangles the drought treatment and vertical bars represent standard errors at the block level. Surveys in different treatments took place at different times and did not always include the same replicates (Online Resource 4); thus, the proportion of squares with living seedlings can increase from one time step to the next. D1 summer drought JuneSeptember 2013; D2 summer drought June-September 2014 some of the observed mortality. Apart from German Pseudotsuga menziesii, seedling survival was so high in the control treatment that living seedlings were recorded in all squares at the end of the experiment in September 2014. At the same time, more than $90 \%$ of the droughted Pinus sylvestris squares contained living seedlings but only $76.6 \%$ of German Pseudotsuga menziesii and $70 \%$ of Pseudotsuga menziesii from the USA. The mortality of the latter two concurs with lower plasticity and limited vertical root proliferation in Pseudotsuga menziesii populations.

\section{Discussion}

Pseudotsuga menziesii is discussed as a non-native alternative to Picea abies for wood production in Central Europe given the projections of a drier future climate (Vor et al. 2015). As a result, its use in plantations has increased in recent years (Forest Europe 2015). Nature conservationists, on the other hand, point to its potential to spread outside plantations (Essl 2005) as well as to the risk of co-introducing exotic organisms, which may potentially jump from their original host to native species (Roques et al. 2006; Schmid et al. 2014). The wide field of uncertainties that lies between the propagation of Pseudotsuga menziesii for wood production and the risks of its natural spread might be reduced by assessing the species' potential to naturally regenerate under current and future climatic conditions. The successful establishment of any (tree) species is primarily driven by its ability to efficiently capture resources such as light, water and nutrients (Rewald and Leuschner 2009; Schulte et al. 2013) and is consequently related to its ability to quickly extend roots and occupy a large soil volume (Mommer et al. 2011; Rajaniemi 2007; Zhang et al. 2012). Root architecture and soil exploitation strategy are thus important components of a species' competitive ability (Messier et al. 2009). The relative competitive ability of individual species growing in mixtures under specific environmental conditions can be estimated in terms of their relative growth rates (Rewald and Leuschner 2009). By the end of the first growing season, Pseudotsuga menziesii seedlings had accumulated slightly more aboveground biomass and were slightly taller than the Pinus sylvestris seedlings, which is likely to be a consequence of a 1.5 -fold higher seed mass. During the following years, however, Pinus sylvestris grew faster both under moist and dry conditions, first in terms of shoot biomass (2012-2013) and then in terms of shoot height (2013-2014; Fig. 2). The growth rate of root biomass was similar in both species and treatments, but Pinus sylvestris exhibited a larger increment of vertical roots under moist conditions as opposed to a higher increment of lateral roots under dry conditions (2013-2014). We confer that, relative to Pinus sylvestris, Pseudotsuga menziesii is less competitive during early establishment both under current levels of summer precipitation as well as under prolonged summer drought. This is corroborated by the fact that seedling survival was lower in Pseudotsuga menziesii (Fig. 5), even though the seedlings 
allocated a considerably larger proportion of biomass to roots than did Pinus sylvestris. Padilla and Pugnaire (2007) demonstrated, however, that the drought resistance of several Mediterranean shrubs is related to rooting depth rather than to root/shoot ratio. Regarding our experiment, all seedlings had lower shoot and root biomass as well as shorter lateral roots after two consecutive summer droughts than did the control seedlings. But, the two species contrasted in terms of absolute vertical root length and how this was affected by drought: after three growing seasons, the vertical roots of Pinus sylvestris extended up to $400 \%$ (control) and $250 \%$ (drought) farther than those of Pseudotsuga menziesii. We are aware that these results might be a consequence of the specific soil conditions in our experiment. But, they are in accordance with greenhouse studies showing that Pseudotsuga menziesii seedlings enhance resource use efficiency under dry conditions rather than altering root architecture (Conlin and van den Driessche 2006), which might be attained by increasing fine root biomass (Tingey et al. 2005). The fact that the root architecture of Pseudotsuga menziesii is unresponsive to abrupt changes in environmental conditions is also known from adult trees (Briggs et al. 2012). Longer roots enable Pinus sylvestris seedlings to reach deeper water pools already during early establishment. Deep water pools are depleted more slowly (Ryel et al. 2008) and enable plants with an extensive root system to outlast transient drought periods (Niinemets 2010). By contrast, 40-50-year-old Pseudotsuga menziesii have been shown to concentrate their root biomass in the top $10-40 \mathrm{~cm}$ of the forest soil (Curt et al. 2001; Eis 1987), which, according to our results, seems to hold for seedlings as well (Fig. 3). The accumulation of fine roots in the upper soil layers seems to allow the species to efficiently exploit soil nutrients (Mauer and Palatova 2012) and might be the reason why Pseudotsuga menziesii, once established, is able to maintain high radial growth rates also under drier conditions (Eilmann and Rigling 2012; Lévesque et al. 2014). Plant available water in the upper soil layers is, on the other hand, strongly tied to single precipitation events (Rennenberg et al. 2006), which may put seedlings at risk of desiccation during long dry periods. Higher drought resistance of old ( $>400$ years) compared to young (0-15 years) Pseudotsuga menziesii stands (Wharton et al. 2009) indicates that drought tolerance changes during the species' life cycle, and there is evidence that these changes are related to root properties. Old, but not young, Pseudotsuga menziesii trees are able to hydraulically redistribute water from deeper soil layers, thus increasing the soil water potential of the top soil and reducing the loss of shallow root function during drought (Domec et al. 2004). The absence of hydraulic redistribution in young Pseudotsuga menziesii might be the consequence of slow root proliferation to deeper soil layers during early life stages, as supported by the short vertical root lengths observed in our study. The susceptibility of Pseudotsuga menziesii to drought during establishment is further aggravated in deep shade, as e.g. in dense stands (Marshall 1986), and on less fertile sites (Sergent et al. 2014). There may also be a genetic component to the drought resistance of individual populations (Eilmann et al. 2013). We found some differences between populations in both species, but they were far outweighed by species or treatment effects. In summary, root architecture seems to hamper the establishment of Pseudotsuga menziesii from seed under very dry conditions due to slow vertical root development, while the dense system of fine roots in the topsoil enables established saplings and mature trees to resist extended drought spells.

\section{Conclusion}

In contrast to Pinus sylvestris, Pseudotsuga menziesii seedlings have a shallow rooting behaviour and lower phenotypic plasticity, which concurs with lower survival rates under dry conditions. On the one hand, this implies that Pseudotsuga menziesii has only a low potential to spontaneously spread from plantations in drier regions of Central Europe, especially since climate change models project longer dry spells in the future (Lindner et al. 2014). On the other hand, extending plantations of Pseudotsuga menziesii from the current suitable range of Picea abies to that of Pinus sylvestris, as suggested by recent reports of higher radial growth rates of adult Pseudotsuga menziesii compared to Pinus sylvestris under dry conditions (Eilmann and Rigling 2012; Lévesque et al. 2014), has to be evaluated carefully. Since the early life stages of Pseudotsuga menziesii rely almost exclusively on the water available in the top soil, costly irrigation would be necessary to establish the species in dryer regions, such as lower elevations in Central Alpine valleys (Eilmann and Rigling 2012). The rooting behaviour of Pinus sylvestris, by contrast, with a distinct taproot that develops early during the seedling stage (Fig. 3), enables the species to quickly reach deeper soil layers (Lyr and Hoffmann 1967; Moser et al. 2015). Likewise, high phenotypic plasticity facilitates the establishment of Pinus sylvestris in disturbed environments despite their heterogeneity and low predictability (Chevin and Lande 2011). On shallow soils and under conditions of limiting water resources, as for instance in dry Central Alpine valleys, it is currently able to colonise and dominate drier locations than Picea abies (Brändli 2010).

Acknowledgments We are grateful to A. Walter, G. Grun and K. Egger for their invaluable help in setting up and running the experiment. We also acknowledge the field and laboratory work of H. Ding, A. Hollaus, A. Käser, K. Kramer, S. Kreuzer, Z. Michalova, A. Perret-Gentil, E. Schnyder, S. Steinböck, D. Trummer, U. Wasem, E. Wilson and many others who helped collecting the seeds and setting up the experiment. Maintenance of the rain shelter facility was provided by A. Moser, WSL Institute for Snow and Avalanche Research SLF, Davos, Switzerland. 


\section{Compliance with ethical standards}

Funding The study was supported by Sciex Fellowhip 10.016 of the Swiss State Secretariat for Education, Research and Innovation to MM and grants 31003A-140966 of the Swiss National Science Foundation to TW and IUT21-4 of the Estonian Ministry of Education and Research to MM.

\section{References}

Bigler C, Bräker OU, Bugmann H, Dobbertin M, Rigling A (2006) Drought as an inciting mortality factor in Scots pine stands of the Valais, Switzerland. Ecosystems 9:330-343. doi:10.1007/s10021005-0126-2

Blada I (1971) Variabilité de la résistance phénotypique des principales populations de Douglas (Pseudotsuga menziesii) de Roumanie aux Rhabdocline pseudotsugae et Phaeocryptopus gäumannii. In: IUFRO, XV Congress, Gainesville, Florida

Brändli U (2010) Schweizerisches Landesforstinventar. Ergebnisse der dritten Erhebung 2004-2006. Eidgenössische Forschungsanstalt für Wald, Schnee und Landschaft WSL, Birmensdorf, und Bundesamt für Umwelt BAFU, Bern

Brang P, Bugmann H, Bürgi A, Mühlethaler U, Rigling A, Schwitter S (2008) Klimawandel als waldbauliche Herausforderung. Schweiz Z Forstwes 159:362-373. doi:10.3188/szf.2008.0362

Braun-Blanquet J (1961) Die inneralpine Trockenvegetation: Von der Provence bis zur Steiermark. Gustav Fischer, Stuttgart

Briggs NA, Kuehne C, Kohnle U, Bauhus J (2012) Root system response of naturally regenerated Douglas-fir (Pseudotsuga menziesii) after complete overstory removal. Can J For Res 42:1858-1864. doi:10.1139/x2012-123

Brodie LC, DeBell DS (2013) Residual densities affect growth of overstory trees and planted Douglas-fir, western hemlock, and western red cedar: results from the first decade. West J Appl For 28:121-127. doi:10.5849/wjaf.12-019

Bürgi A, Diez C (1986) Übersicht über den Exotenanbau in der Schweiz aufgrund einer Umfrage vom Herbst/Winter 1984/85. Schweiz Z Forstwes 137:833-851

Bussotti F, Pollastrini M, Holland V, Bruggemann W (2015) Functional traits and adaptive capacity of European forests to climate change. Environ Exp Bot 111:91-113. doi:10.1016/j.envexpbot.2014.11.006

Chen P-Y, Welsh C, Hamann A (2010) Geographic variation in growth response of Douglas-fir to interannual climate variability and projected climate change. Glob Change Biol 16:3374-3385. doi:10.1111/j.1365-2486.2010.02166.x

Chevin LM, Lande R (2011) Adaptation to marginal habitats by evolution of increased phenotypic plasticity. J Evol Biol 24:1462-1476. doi:10.1111/j.1420-9101.2011.02279.x

Conlin TSS, van den Driessche R (2006) Influence of nutrient supply and water vapour pressure on root architecture of Douglas-fir and western hemlock seedlings. Funct Plant Biol 33:941-948. doi:10.1071 /fp05317

Curt T, Lucot E, Bouchaud M (2001) Douglas-fir root biomass and rooting profile in relation to soils in a mid-elevation area (Beaujolais mounts, France). Plant Soil 233:109-125. doi:10.1023 /a:1010333308738

Domec JC, Warren JM, Meinzer FC, Brooks JR, Coulombe R (2004) Native root xylem embolism and stomatal closure in stands of Douglas-fir and ponderosa pine: mitigation by hydraulic redistribution. Oecologia 141:7-16. doi:10.1007/s00442-004-1621-4
Eilmann B, Rigling A (2012) Tree-growth analyses to estimate tree species' drought tolerance. Tree Physiol 32:178-187. doi:10.1093 /treephys/tps004

Eilmann B, de Vries SMG, den Ouden J, Mohren GMJ, Sauren P, SassKlaassen U (2013) Origin matters! Difference in drought tolerance and productivity of coastal Douglas-fir (Pseudotsuga menziesii (Mirb.)) provenances. For Ecol Manag 302:133-143. doi:10.1016 /j.foreco.2013.03.031

Eis S (1987) Root systems of older immature hemlock, cedar, and Douglas-fir. Can J For Res 17:1348-1354. doi:10.1139/x87-208

Ess1 F (2005) Distribution, status and habitat preference of subspontaneous Douglas fir stands (Pseudotsuga menziesii) in Austria. Phyton 45:117-143

Ferrell WK, Woodard ES (1966) Effects of seed origin on drought resistance of Douglas-fir (Pseudotsuga menziesii (Mirb.) Franco). Ecology 47:499-503. doi:10.2307/1932994

Fischer A (2008) Die Eignung der Douglasie im Hinblick auf den Klimawandel. LWF Wissen 59:63-66

Forest Europe (2015) State of Europe's forests 2015. Ministerial conference on the protection of forests in Europe, 2015

Fort F, Cruz P, Jouany C (2014) Hierarchy of root functional trait values and plasticity drive early-stage competition for water and phosphorus among grasses. Funct Ecol 28:1030-1040. doi:10.1111/13652435.12217

González-García S, Bonnesoeur V, Pizzi A, Feijoo G, Moreira MT (2013) The influence of forest management systems on the environmental impacts for Douglas-fir production in France. Sci Total Environ 461: 681-692. doi:10.1016/j.scitotenv.2013.05.069

Hijmans RJ, Cameron SE, Parra JL, Jones PG, Jarvis A (2005) Very high resolution interpolated climate surfaces for global land areas. Int $\mathrm{J}$ Climatol 25:1965-1978. doi:10.1002/joc. 1276

Hoff RJ (1987) Susceptibility of inland Douglas-fir to Rhabdocline needle cast. Forest Service, Research Note INT-375. U.S. Department of Agriculture

Hothorn T, Bretz F, Westfall P (2008) Simultaneous inference in general parametric models. Biom J 50:346-363. doi:10.1002 /bimj.200810425

Kowarik I, Rabitsch W (2010) Biologische Invasionen: Neophyten und Neozoen in Mitteleuropa, 2nd edn. Ulmer, Stuttgart

Lévesque M, Rigling A, Bugmann H, Weber P, Brang P (2014) Growth response of five co-occurring conifers to drought across a wide climatic gradient in Central Europe. Agric For Meteorol 197:1-12. doi:10.1016/j.agrformet.2014.06.001

Lindner M, Fitzgerald JB, Zimmermann NE, Reyer C, Delzon S, van der Maaten E, Schelhaas M-J, Lasch P, Eggers J, van der MaatenTheunissen M, Suckow F, Psomas A, Poulter B, Hanewinkel M (2014) Climate change and European forests: what do we know, what are the uncertainties, and what are the implications for forest management? J Environ Manag 146:69-83. doi:10.1016/j. jenvman.2014.07.030

Littell JS, Peterson DL, Tjoelker M (2008) Douglas-fir growth in mountain ecosystems: water limits tree growth from stand to region. Ecol Monogr 78:349-368. doi:10.1890/07-0712.1

Little ELJ (1971) Atlas of United States trees: conifers and important hardwoods. Report No. 1146. U.S. Department of Agriculture

Lyr H, Hoffmann G (1967) Growth rates and growth periodicity of tree roots. Int Rev For Res 2:181-236

Mailly D, Kimmins JP (1997) Growth of Pseudotsuga menziesii and Tsuga heterophylla seedlings along a light gradient: resource allocation and morphological acclimation. Can J Bot 75:1424-1435

Marshall JD (1986) Drought and shade interact to cause fine-root mortality in Douglas-fir seedlings. Plant Soil 91:51-60

Mauer O, Palatova E (2012) Root system development in Douglas fir (Pseudotsuga menziesii (Mirb.) Franco) on fertile sites. J For Sci $58: 400-409$ 
Messier C, Coll L, Poitras-Larivière A, Bélanger N, Brisson J (2009) Resource and non-resource root competition effects of grasses on early- versus late-successional trees. J Ecol 97:548-554. doi:10.1111/j.1365-2745.2009.01500.x

Mommer L, Visser EJW, van Ruijven J, de Caluwe H, Pierik R, de Kroon $\mathrm{H}$ (2011) Contrasting root behaviour in two grass species: a test of functionality in dynamic heterogeneous conditions. Plant Soil 344: 347-360. doi:10.1007/s11104-011-0752-8

Moser B, Kipfer T, Richter S, Egli S, Wohlgemuth T (2015) Drought resistance of Pinus sylvestris seedlings conferred by plastic root architecture rather than ectomycorrhizal colonisation. Ann For Sci 72:303-309. doi:10.1007/s13595-014-0380-6

Nabel MR, Newton M, Cole EC (2013) Abundance of natural regeneration and growth comparisons with planted seedlings $10-13$ years after commercial thinning in 50-year-old Douglas-fir, Douglas-fir/ western hemlock, Oregon coast range. For Ecol Manag 292:96-110. doi:10.1016/j.foreco.2012.12.009

Niinemets U (2010) Responses of forest trees to single and multiple environmental stresses from seedlings to mature plants: past stress history, stress interactions, tolerance and acclimation. For Ecol Manag 260:1623-1639. doi:10.1016/j.foreco.2010.07.054

Ozenda P (1985) La végétation de la chaîne alpine dans l'espace montagnard européen. Masson, Paris

Padilla FM, Pugnaire FI (2007) Rooting depth and soil moisture control Mediterranean woody seedling survival during drought. Funct Ecol 21:489-495. doi:10.1111/j.1365-2435.2007.01267.x

Poorter H, Buehler J, van Dusschoten D, Climent J, Postma JA (2012) Pot size matters: a meta-analysis of the effects of rooting volume on plant growth. Funct Plant Biol 39:839-850. doi:10.1071/fp12049

Preisig CL, Carlson WC, Promnitz LC (1979) Comparative root-system morphologies of seeded-in-place, bareroot, and containerized Douglas-fir seedlings after outplanting. Can J For Res 9:399-405

R Core Team (2015) R: A language and environment for statistical computing. R Foundation for Statistical Computing, Vienna

Rajaniemi TK (2007) Root foraging traits and competitive ability in heterogeneous soils. Oecologia 153:145-152. doi:10.1007/s00442007-0706-2

Rennenberg H, Loreto F, Polle A, Brilli F, Fares S, Beniwal RS, Gessler A (2006) Physiological responses of forest trees to heat and drought. Plant Biol 8:556-571. doi:10.1055/s-2006-924084

Rewald B, Leuschner C (2009) Does root competition asymmetry increase with water availability? Plant Ecology \& Diversity 2:255264. doi:10.1080/17550870903022865

Richardson DM, Rejmánek M (2004) Conifers as invasive aliens: a global survey and predictive framework. Divers Distrib 10:321-331. doi:10.1111/j.1366-9516.2004.00096.x

Richter S, Kipfer T, Wohlgemuth T, Guerrero C, Ghazoul J, Moser B (2012) Phenotypic plasticity facilitates resistance to climate change in a highly variable environment. Oecologia 169:269-279. doi:10.1007/s00442-011-2191-x

Rigling A, Bigler C, Eilmann B, Feldmeyer-Christe E, Gimmi U, Ginzler C, Graf U, Mayer P, Vacchiano G, Weber P, Wohlgemuth T, Zweifel R, Dobbertin M (2013) Driving factors of a vegetation shift from Scots pine to pubescent oak in dry alpine forests. Glob Change Biol 19:229-240. doi:10.1111/gcb.12038

Roques A, Auger-Rozenberg MA, Boivin S (2006) A lack of native congeners may limit colonization of introduced conifers by indigenous insects in Europe. Can J For Res 36:299-313. doi:10.1139 /x05-277

Ryel RJ, Ivans CY, Peek MS, Leffler AJ (2008) Functional differences in soil water pools: a new perspective on plant water use in water- limited ecosystems. In: Luttge U, Beyschlag W, Murata J (eds) Progress in Botany 69, vol 69, pp. 397-422

Schmid M, Pautasso M, Holdenrieder O (2014) Ecological consequences of Douglas fir (Pseudotsuga menziesii) cultivation in Europe. Eur J For Res 133:13-29. doi:10.1007/s10342-013-0745-7

Schüler S, Falk W, Koskela J, Lefèvre F, Bozzano M, Hubert J, Kraigher H, Longauer R, Olrik DC (2014) Vulnerability of dynamic genetic conservation units of forest trees in Europe to climate change. Glob Change Biol 20:1498-1511. doi:10.1111/gcb.12476

Schulte MJD, Matyssek R, Gayler S, Priesack E, Grams TEE (2013) Mode of competition for light and water amongst juvenile beech and spruce trees under ambient and elevated levels of O-3 and CO2. Trees-Struct Funct 27:1763-1773. doi:10.1007/s00468-0130922-9

Sergent A-S, Rozenberg P, Bréda N (2014) Douglas-fir is vulnerable to exceptional and recurrent drought episodes and recovers less well on less fertile sites. Ann For Sci 71:697-708. doi:10.1007/s13595-012$0220-5$

Singer MJ, Munns DN (2006) Soils: an introduction, 6th edn. Pearson Prentice Hall, Upper Saddle River

Stimm B, Dong PH (2001) The Kaiserslautern Douglas fir provenance trial after nine decades of observation. Forstwiss Centbl 120:173186. doi:10.1007/bf02796090

Tingey DT, Phillips DL, Johnson MG, Rygiewicz PT, Beedlow PA, Hogsett WE (2005) Estimates of Douglas-fir fine root production and mortality from minirhizotrons. For Ecol Manag 204:359-370. doi:10.1016/j.foreco.2004.09.010

Tschopp T, Holderegger R, Bollmann K (2015) Auswirkungen der Douglasie auf die Waldbiodiversität. Schweiz Z Forstwes 166:915. doi:10.3188/szf.2015.0009

Vacchiano G, Motta R (2015) An improved species distribution model for scots pine and downy oak under future climate change in the NW Italian alps. Ann For Sci 72. doi:10.1007/s13595-014-0439-4

Vacchiano G, Garbarino M, Mondino EB, Motta R (2012) Evidences of drought stress as a predisposing factor to Scots pine decline in Valle d'Aosta (Italy. Eur J For Res 131:989-1000. doi:10.1007/s10342011-0570-9

Valladares F, Sánchez-Gómez D, Zavala MA (2006) Quantitative estimation of phenotypic plasticity: bridging the gap between the evolutionary concept and its ecological applications. J Ecol 94:11031116. doi:10.1111/j.1365-2745.2006.01176.x

Vor T, Spellmann H, Bolte A, Ammer C (2015) Potenziale und Risiken eingeführter Baumarten: Baumartenportaits mit naturschutzfachlicher Bewertung. Gött Forstwiss 7:1-296

Wharton S, Schroeder M, Bible K, Falk M, Paw KT (2009) Stand-level gas-exchange responses to seasonal drought in very young versus old Douglas-fir forests of the Pacific northwest, USA. Tree Physiol 29:959-974. doi:10.1093/treephys/tpp039

Wilcox HE (1968) Morphological studies of the root of red pine, Pinus resinosa I. Growth characteristics and patterns of branching. Am J Bot 55:247-254

Wohlgemuth T (2015) Climate change and tree responses in central European forests. Ann For Sci 72. doi:10.1007/s13595-015-0474-9

Zhang Y, Ma XH, Zhou ZC (2012) The influence of light conditions and interspecific competition on the root foraging traits and seedling growth of two tree species. Plant Biosyst 146:7-14. doi:10.1080 /11263504.2011.593199

Zuber T (2007) Untersuchungen zum Wasserhaushalt eines Fichtenwaldstandorts unter Berücksichtigung der Humusauflage. $\mathrm{PhD}$ thesis. Universität Bayreuth, Bayreuth 